\title{
Performance of a New Magnetic Chitosan Nanoparticle to Remove Arsenic and Its Separation from Water
}

\author{
Cheng Liu, ${ }^{1,2}$ Bin Wang, ${ }^{2}$ Yang Deng, ${ }^{3}$ Biao Cui, ${ }^{1}$ Jie Wang, Wei Chen, ${ }^{1,2}$ and Si-yuan He \\ ${ }^{1}$ Key Laboratory of Integrated Regulation and Resource Development on Shallow Lakes, Ministry of Education, \\ Hohai University, Nanjing 210098, China \\ ${ }^{2}$ College of Environment, Hohai University, Nanjing 210098, China \\ ${ }^{3}$ Department of Earth and Environmental Studies, Montclair State University, Montclair, NJ 07043, USA
}

Correspondence should be addressed to Wei Chen; cw5826@hhu.edu.cn

Received 8 April 2015; Revised 25 September 2015; Accepted 30 September 2015

Academic Editor: Tae-Oh Kim

Copyright (C) 2015 Cheng Liu et al. This is an open access article distributed under the Creative Commons Attribution License, which permits unrestricted use, distribution, and reproduction in any medium, provided the original work is properly cited.

Removal performance of arsenic in water by a novel magnetic chitosan nanoparticle (MCNP) with a diameter of about $10 \mathrm{~nm}$, including adsorption kinetics, adsorption isotherm, main influencing factors, and regeneration effects, was investigated. In addition, the effective separation way for MCNP particles and the new application mode were developed to prompt the application of MCNP. The results showed that MCNP exhibited excellent ability to remove As(V) and As(III) from water in a wide range of initial concentrations, MCNP removed arsenic rapidly with more than $95 \%$ of arsenic adsorbed in initial 15 min, and the whole process fitted well to the pseudo-second-order model. The Langmuir model fits the equilibrium data better than the Freundlich isotherm model and the maximum adsorption capacities of $\mathrm{As}(\mathrm{V})$ and $\mathrm{As}(\mathrm{III})$ were $65.5 \mathrm{mg} / \mathrm{g}$ and $60.2 \mathrm{mg} / \mathrm{g}$, respectively. The saturated MCNP could be easily regenerated and kept more than $95 \%$ of initial adsorption capacity stable after 10 regeneration cycles. A new magnetic material separation method was established to separate MCNP effectively. The continuous-operation instrument developed based on the MCNP could operate stably and guarantee that the concentration of arsenic meets the guideline limit of arsenic in drinking water regulated by the WHO.

\section{Introduction}

Arsenic has been found in the groundwater in many regions of the world such as Bangladesh [1], India [2], and other countries [3]. In China, approximately 20 million people are at risk of drinking As-contaminated water from tube wells which resulted in arsenic poisoning being the serious endemic disease [4-6]. The arsenic presence in drinking water is extremely detrimental to human health [7]; most countries are implementing the maximum permissible limit of arsenic in drinking water of $10 \mu \mathrm{g} / \mathrm{L}$ recommended by the World Health Organization.

Several methods, just like precipitation [8], membrane separation, ion exchange, and adsorption [9-11], have been applied to remove excessive arsenic from water. Adsorption has received special attention due to its good removal effects and easy operation [12]. The characteristics of absorbents played important role in their removal performance. Chitosan is a poly-N-glucosamine species obtained by the deacetylation of chitin, the most abundant aminopolysaccharide existing in the environment. It is highly hydrophilic and is characterized by a flexible polymer chain and by a large number of hydroxyl and amino groups that represent potential adsorption sites.

Chitosan derivatives, obtained through chemical and physical modifications, cross-linking, modifying its physical structure, immobilizing it on insoluble supports, or impregnating it with metals, are preferred. Chitosan and chitosan derivatives, as kinds of arsenic-removing agents, were receiving more and more attention. Nanochitosan [13], zerovalent iron encapsulated chitosan [14], mixed metal oxide impregnated chitosan beads (MICB) [15], $\mathrm{TiO}_{2}$-impregnated chitosan bead [16], aluminum and doping chitosan-Fe(III) hydrogel [17], and chitosan complexed with transition metal 
ions [18] were used to remove arsenic from water in recent studies. The amino group existing in chitosan has been reported to be an efficient heavy metal scavenger [19]. Therefore, greater surface area and amine functions may cause better removal effects of arsenic. Two ways could be used to increase the surface area of the absorbents; decreasing the particle size was one of the choices. However, smaller particle size may cause difficulty in the separation and influence the water quality of the effluent. In our recent research, a novel magnetic chitosan nanoparticle (MCNP) was prepared by one-step in situ coprecipitation at low temperature and normal atmosphere, which showed significant adsorption potential for the removal of humic acid (HA) from aqueous solution [20,21], but the removal performance for arsenic and subsequent separation have not been examined.

Herein, the uptake capacity and adsorption kinetics for $\mathrm{As}(\mathrm{V})$ and $\mathrm{As}(\mathrm{III})$ by magnetic chitosan nanoparticle (MCNP) and its regeneration efficiency were investigated. New separation method of MCNP was explored in the meantime. Furthermore, removal of arsenic from real underground water by the adsorbent was also evaluated.

\section{Material and Methods}

2.1. Raw Water and Chemicals. As(III) and As(V) standard reference sodium arsenite $(1000 \mathrm{mg} / \mathrm{L})$ and chitosan with a deacetylation degree of $80-95 \%$ were purchased from Sinopharm Chemical Reagent Co. Ltd., China, and used without any further purification. All the other chemicals used were of analytical grade. Distilled water was used throughout the study.

Raw water sample was taken from Bayannur city in Inner Mongolia of China. The values of main water parameters for the raw water were shown in Table 1.

2.2. Preparation of MCNP. The MCNP was synthesized as the methods described in our former study [20], with the main steps as follows. Chitosan solution was prepared by dissolving $0.5 \mathrm{~g}$ of chitosan in $200 \mathrm{~mL}$ of $0.5 \%(\mathrm{v} / \mathrm{v})$ acetic acid solution with continuous stirring. $4.7 \mathrm{~g}$ of $\mathrm{FeCl}_{3} \cdot 6 \mathrm{H}_{2} \mathrm{O}$ and $2.4 \mathrm{~g}$ of $\mathrm{FeSO}_{4} \cdot 7 \mathrm{H}_{2} \mathrm{O}$, which were dissolved in $22 \mathrm{~mL}$ of distilled water, respectively, were added to the chitosan solution by stirring at $1000 \mathrm{rpm}$ for $20 \mathrm{~min}$ in a water bath at $40^{\circ} \mathrm{C}$. After that, $40 \mathrm{~mL}$ of $28 \%(\mathrm{~m} / \mathrm{v})$ ammonia was added dropwise into the reaction system. After $20 \mathrm{~min}$, the temperature of the reaction system was adjusted to $60^{\circ} \mathrm{C}$, and then $6 \mathrm{~mL}$ of epichlorohydrin was added to the system with continuous stirring at $1000 \mathrm{rpm}$ for $3 \mathrm{~h}$. The resulting MCNP was separated by a magnet field. Finally, the obtained MCNP was washed by $0.5 \%(\mathrm{v} / \mathrm{v})$ acetic acid, distilled water, and alcohol for three times, respectively, and dried in an oven at $60^{\circ} \mathrm{C}$ till reaching constant weight.

The main parameters of MCNP are shown in Table 2. As a comparison, the result of recent similar study is shown in the table either. The other important parameter, the total amount of amine groups, or the degree of deacetylation (DDA\%) of MCNP can be determined with the carbon-to-nitrogen ratio $(\mathrm{C} / \mathrm{N}$ ratio) $[22]$ that resulted from XPS.
TABLE 1: Characteristics of the natural water sample from Inner Mongolia of China.

\begin{tabular}{|c|c|}
\hline Items & Value \\
\hline As $(\mathrm{mg} / \mathrm{L})$ & $0.03-0.032$ \\
\hline $\mathrm{F}(\mathrm{mg} / \mathrm{L})$ & $0.52-0.58$ \\
\hline $\mathrm{Cl}(\mathrm{mg} / \mathrm{L})$ & $91.5-98 . .6$ \\
\hline $\mathrm{SO} 4^{2-}(\mathrm{mg} / \mathrm{L})$ & $57.2-63.5$ \\
\hline $\mathrm{Hg}(\mathrm{mg} / \mathrm{L})$ & 0.006 \\
\hline $\mathrm{Pb}(\mathrm{mg} / \mathrm{L})$ & - \\
\hline $\mathrm{Mn}(\mathrm{mg} / \mathrm{L})$ & $0.01-0.015$ \\
\hline $\mathrm{Fe}(\mathrm{mg} / \mathrm{L})$ & $0.21-0.36$ \\
\hline $\mathrm{Cu}(\mathrm{mg} / \mathrm{L})$ & $0.003-0.005$ \\
\hline $\mathrm{Na}(\mathrm{mg} / \mathrm{L})$ & $43.5-51.3$ \\
\hline $\mathrm{Ca}(\mathrm{mg} / \mathrm{L})$ & $88.9-95.4$ \\
\hline $\mathrm{Mg}(\mathrm{mg} / \mathrm{L})$ & 0.0213 \\
\hline Total hardness $\left(\mathrm{mg} / \mathrm{LCaCO}_{3}\right)$ & $432.5-465.8$ \\
\hline $\mathrm{UV}_{254}\left(\mathrm{~cm}^{-1}\right)$ & 0.046 \\
\hline $\mathrm{pH}$ & $7.3-7.5$ \\
\hline $\mathrm{DOC}(\mathrm{mg} / \mathrm{L})$ & $0.57-0.86$ \\
\hline
\end{tabular}

TABLE 2: The main characterization of two kinds of magnetic chitosan.

\begin{tabular}{lcc}
\hline Parameters & MCNP & MICB [19] \\
\hline Diameter $(\mathrm{nm})$ & $6-10$ & $2.5 \times 10^{6}$ \\
Saturation magnetization $(\mu / \mathrm{g})$ & 44.43 & 17.14 \\
Specific gravity & 1.002 & - \\
Specific surface area $\left(\mathrm{m}^{2} / \mathrm{g}\right)$ & 108.32 & 50.20 \\
Total pore volume $\left(\mathrm{cm}^{3} / \mathrm{g}\right)$ & 0.40 & 0.052 \\
Proportion of chitosan $(\%)$ & 29.2 & - \\
Point of zero & 6.34 & - \\
Magnetic powder category & $\mathrm{Fe}_{3} \mathrm{O}_{4}$ & $\mathrm{Fe}_{3} \mathrm{O}_{4}$ \\
\hline
\end{tabular}

2.3. Arsenic Adsorption Experiments. Similar experiment method as in former study [19] was used for contrast with other studies. Adsorption experiments were conducted in conical flasks containing $100 \mathrm{~mL}$ of $\mathrm{As}(\mathrm{III})$ and $\mathrm{As}(\mathrm{V})$ solution of variable initial concentrations from 0.2 to $50 \mathrm{mg} / \mathrm{L}$ and $0.05 \mathrm{~g}$ of MCNP at specified temperature. The flasks were shaken on a shaker equipped with thermostat at $150 \mathrm{rpm}$. After predetermined contact time, the aqueous sample was separated by a magnet, and the residual concentration of As(III) and As(V) in the supernatant was measured by inductively coupled plasma atomic emission spectroscopy (ICP-AES, the detection limit of $0.001 \mathrm{mg} / \mathrm{L}$, Intrepid II, Thermofisher, USA).

The adsorption capacity at equilibrium of the adsorbents for arsenic was calculated according to the following:

$$
q_{t}=\frac{\left(C_{0}-C_{t}\right) V}{m}
$$

where $C_{0}(\mathrm{mg} / \mathrm{L})$ is the initial concentration of arsenic, $C_{t}$ $(\mathrm{mg} / \mathrm{L})$ is the instant concentration of arsenic at any time $t, V$ (L) is the volume of solution, and $m(\mathrm{~g})$ is the mass of MCNP. 


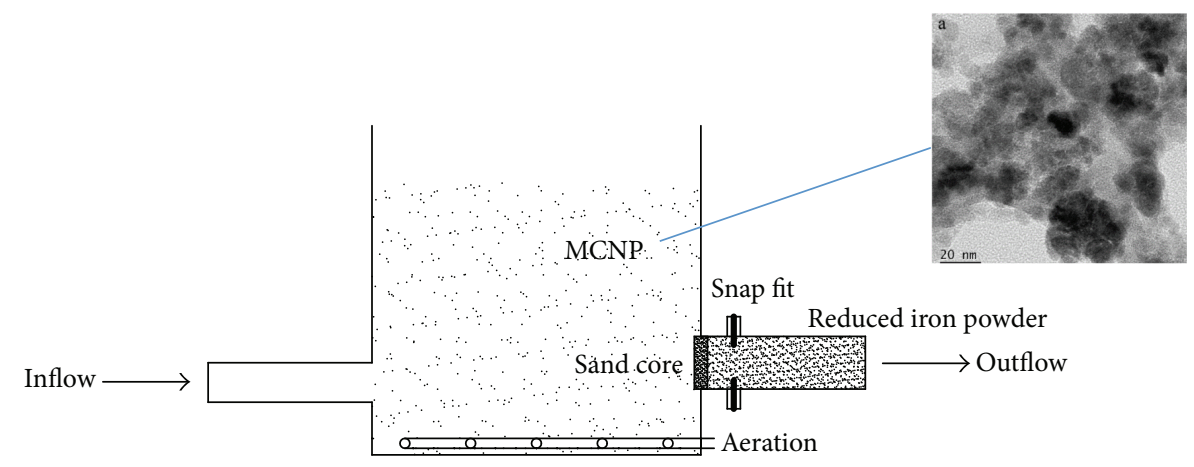

FIGURE 1: Diagram of continuous-operation instrument using MCNP as the arsenic removal agents.

To estimate adsorption rate for the uptake of As(III) and $\mathrm{As}(\mathrm{V})$ by MCNP, time-dependent adsorption studies were conducted. The kinetics adsorption on both As(III) and $\mathrm{As}(\mathrm{V})$ was investigated using different initial arsenic concentrations of $\sim 2.0 \mathrm{mg} / \mathrm{L}, \sim 5.0 \mathrm{mg} / \mathrm{L}$, and $\sim 10.0 \mathrm{mg} / \mathrm{L}$, respectively, with $1.0 \mathrm{~g} / \mathrm{L}$ of adsorbent and a total solution volume of $750 \mathrm{~mL} \mathrm{As(III)} \mathrm{and} \mathrm{As(V)} \mathrm{solutions} \mathrm{immersed} \mathrm{in}$ $1000 \mathrm{~mL}$ glass vessel. The $\mathrm{pH}$ of the solutions was chosen at $6.8 \pm 0.2$ for optimal adsorption. The mixtures were shaken at $140 \mathrm{rpm}$ and approximately $5 \mathrm{~mL}$ aliquots were then removed periodically for measuring the corresponding arsenic concentration, in order to calculate their timedependent adsorption capacity.

2.4. Regeneration of MCNP. Regeneration of arsenic saturated adsorbents was achieved using sodium hydroxide solution according to former study. As to the special characteristic of MCNP, regeneration conditions need to be optimized, especially for the proper concentration of sodium hydroxide solution and reaction time. The adsorption performance of the regenerated MCNP was evaluated with both adsorption capacity and removal efficiency for the initial arsenic concentration of $1 \mathrm{mg} / \mathrm{L} \mathrm{As}(\mathrm{V})$ and $\mathrm{As}(\mathrm{III})$ solutions and adsorbent dose of $1 \mathrm{~g} / \mathrm{L}$ at $\mathrm{pH} 6.8 \pm 0.2$ for $0.5 \mathrm{~h}$.

2.5. Separation of MCNP. Magnetic field was one of the most popular ways to separate magnetic materials; however, it was limited in the practice of application, especially to the continuous operation. The down-flow filtration with iron powder was used to hold up the MCNP, during which the depth of iron powder was investigated for the influence of the separation effects. The diameter of powder used in the experiment was $1-2 \mathrm{~mm}$. Turbidity, particle count of certain diameter, and particle size distribution were used to estimate the separation effect of the filtration. Turbidity meter $(2010 \mathrm{~N}$, Hach), particle counting instrument (IBR), and Zetasizer Nano ZS90 instrument (Malvern Instruments Ltd., UK) were used to determine the above index.

2.6. Continuous Dynamic Adsorption Experiments. Continuous dynamic adsorption experiments were conducted in a Perspex device (as shown in Figure 1). The MCNP were added into the water as the concentration of $5 \mathrm{~g} / \mathrm{L}$ and mixed through the way of pulse aeration. The influent raw water blended with the water containing MCNP and flowed counterclockwise due to the heterogeneous intensity of aeration. The effluent was collected from the devices outlet at regular intervals of time and the concentrations of arsenic, turbidity, and metal ions in the effluent solution were measured immediately. The outlet was composed of sand core filter and iron powder filter consequently, and both could be exchanged if needed. The used MCNP were taken away for regeneration and the same dosages of regenerated particles were put back into the instrument at certain time. The exchanged iron powder filter was flushed with water and air; the backwash water was collected together to reclaim, regenerate, and reuse the MCNP accordingly. All the experiments were operated at room temperature.

\section{Results and Discussion}

\subsection{Performance of MCNP to Remove Arsenic from Water}

3.1.1. Adsorption Kinetics for Arsenic Removal from Synthetic Water. Figure 2 shows the change of adsorbed arsenic as a function of contact time.

As seen from Figure 2, MCNP adsorbs both As(V) and As(III) with a fast speed. More than $95 \%$ of the equilibrium adsorption capacity for $\mathrm{As}(\mathrm{V})$ and $\mathrm{As}(\mathrm{III})$ was achieved within $15 \mathrm{~min}$, which was significantly less than that of MICB [19]. In addition, little difference existed for the As(V) and As(III) adsorption process. As shown from Table 2, the main differences between the MCNP and MICB were the particle size and surface area. MCNP has smaller particle diameter and larger surface area than MICB, which increased the contact area of MCNP and arsenic ion and shortened the migration distance of arsenic molecular. Pseudo-firstorder and pseudo-second-order kinetic models were used to simulate the kinetics and quantify the changes of arsenic adsorption (Table 3). The pseudo-first-order model fitted the experimental data better than the pseudo-second-order one for both As(V) and As(III), which was different from that of MICB. Because the MCNP had little pores, the adsorption process may consist of two processes: (1) the transport of arsenic from bulk solution to the surface of MCNP and (2) the attachment of arsenic to MCNP. According to former 
TABLE 3: Kinetics parameters for As(V) and As(III) adsorption on the MCNP and MICB with various initial arsenic concentrations.

\begin{tabular}{|c|c|c|c|c|c|c|c|c|}
\hline \multirow{2}{*}{ Arsenic species } & \multirow{2}{*}{ Initial concentration $(\mathrm{mg} / \mathrm{L})$} & \multirow{2}{*}{ Adsorbent category } & \multicolumn{3}{|c|}{ First-order kinetics } & \multicolumn{3}{|c|}{ Second-order kinetics } \\
\hline & & & $k_{1}(1 / \mathrm{min})$ & $q_{e}$ & $R^{2}$ & $k_{2}(1 / \min )$ & $q_{e}$ & $R^{2}$ \\
\hline \multirow{6}{*}{$\mathrm{As}(\mathrm{V})$} & \multirow{2}{*}{2.02} & MICB & 0.00447 & 0.09829 & 0.923 & 0.0184 & 2.03 & 0.999 \\
\hline & & MCNP & 0.66894 & 2.0381 & 0.999 & 1.47387 & 2.05 & 0.988 \\
\hline & \multirow{2}{*}{5.28} & MICB & $5.37 \times 10^{-3}$ & 2.762 & 0.786 & $6.985 \times 10^{-3}$ & 5.229 & 0.999 \\
\hline & & MCNP & 0.80321 & 5.07219 & 0.999 & 1.35289 & 5.09 & 0.989 \\
\hline & \multirow{2}{*}{10.73} & MICB & $5.82 \times 10^{-3}$ & 3.549 & 0.648 & $5.80 \times 10^{-3}$ & 10.619 & 0.999 \\
\hline & & MCNP & 1.03997 & 10.1352 & 0.999 & 0.83557 & 10.21 & 0.98 \\
\hline \multirow{6}{*}{$\operatorname{As}(\mathrm{III})$} & \multirow{2}{*}{2.01} & MICB & 0.00937 & 0.6384 & 0.886 & 0.0152 & 2.03 & 0.999 \\
\hline & & MCNP & 0.67013 & 2.00007 & 0.999 & 2.0559 & 2.002 & 0.96 \\
\hline & \multirow{2}{*}{5.19} & MICB & 0.00898 & 3.9759 & 0.927 & $6.659 \times 10^{-3}$ & 5.089 & 0.999 \\
\hline & & MCNP & 0.80656 & 4.99143 & 0.999 & 1.10786 & 5.01 & 0.985 \\
\hline & \multirow{2}{*}{10.58} & MICB & 0.00963 & 7.9044 & 0.960 & $3.07 \times 10^{-3}$ & 9.859 & 0.999 \\
\hline & & MCNP & 1.19382 & 9.68389 & 0.999 & 1.00456 & 9.724 & 0.982 \\
\hline
\end{tabular}

Note: the data of MICB is taken from the study of Wang et al. [19].

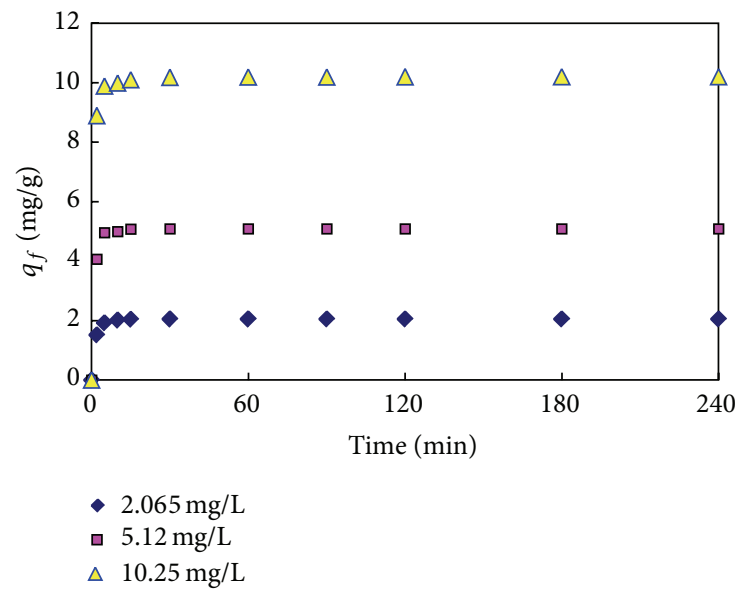

(a)

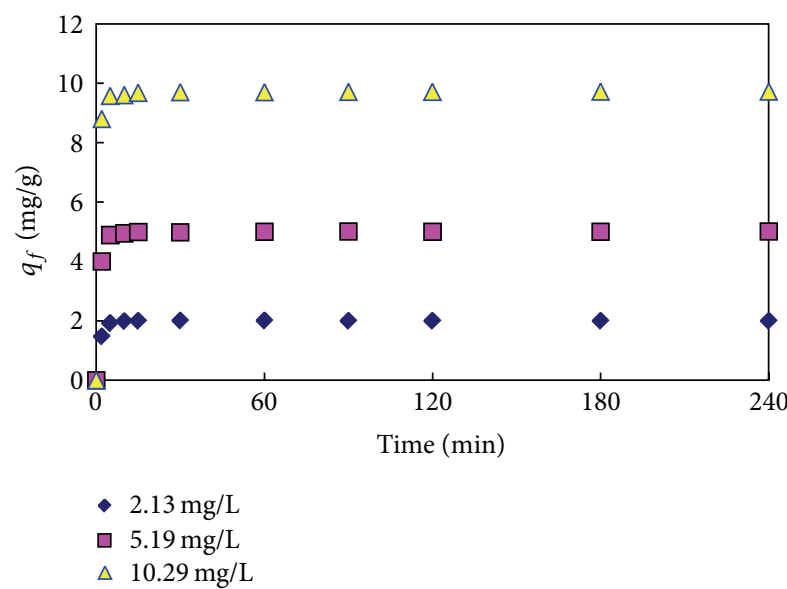

(b)

Figure 2: Kinetics of (a) As(V) and (b) As(III) removal by the MCNP at different initial concentrations: $\sim 2 \mathrm{mg} / \mathrm{L}, \sim 5 \mathrm{mg} / \mathrm{L}$, and $\sim 10 \mathrm{mg} / \mathrm{L}$, respectively. Adsorbent dose: $1 \mathrm{~g} / \mathrm{L}, \mathrm{pH}: 6.8 \pm 0.2$, and temperature: $25^{\circ} \mathrm{C}$.

studies, the attachment of arsenic molecules to the protonated amino groups $\left(-\mathrm{NH}_{3}{ }^{+}\right)$on the chitosan was quite instant. Due to higher surface area and shorter transport distance, the effects of mass transport were decreased significantly and the attachment of arsenic onto MCNP became the main limited step. Therefore, the removal process was found to follow the pseudo-first-order kinetic model. As seen in Table 3, the removal rate of MCNP was significantly higher than that of $\operatorname{MICB}(0.66894,0.67013$ versus $0.00447,0.00937$ for $2 \mathrm{mg} / \mathrm{L}$ of $\mathrm{As}(\mathrm{V})$ and $\mathrm{As}(\mathrm{III})$, resp.). In addition, proper agitation during the removal process was needed to further accelerate the removal rates of arsenic according to the analysis for removal process, for that proper agitation could thin the aqueous layer and shorten the migration distance from the water bulk to the particle surface.

As to the two kinds of arsenic, similar values of $k_{1}$ for $\mathrm{As}(\mathrm{V})$ and $\mathrm{As}(\mathrm{III})$ adsorption were found under the same experimental conditions, which is different from other studies. According to the adsorption process of arsenic onto MCNP, the relatively shorter distance and abundance of accessible adsorption sites may cause the remarkable difference.

3.1.2. Adsorption Isotherms for Arsenic Removal from Synthetic Water. The isotherm points at different equilibrium concentration, the fitting curves, and adsorption parameters obtained from the isotherms are shown in Figure 3 and the maximum adsorption capacities of the absorbents derived from chitosan in recent studies are shown in Table 4. The Langmuir model could be used to describe the adsorption behavior of both $\mathrm{As}(\mathrm{V})$ and $\mathrm{As}(\mathrm{III})$ on the MCNP. Maximum adsorption capacities were calculated from the Langmuir equation to be $65.5 \mathrm{mg} / \mathrm{g}$ for $\mathrm{As}(\mathrm{V})$ and $60.2 \mathrm{mg} / \mathrm{g}$ for As(III), respectively, which were about two times higher than those of MICB at the similar applied experimental conditions and higher than other chitosan adsorbents except for some impregnated chitosan derivation. The reason may lie in two aspects: one is the fact that the value of the specific area of 
TABLE 4: Comparison of adsorption capacity with different granular adsorbents.

\begin{tabular}{|c|c|c|c|c|c|}
\hline \multirow{2}{*}{ Granular adsorbent } & \multirow{2}{*}{$C_{\text {initial }}(\mathrm{mg} / \mathrm{L})$} & \multicolumn{2}{|c|}{$q_{e, \max }(\mathrm{mg} / \mathrm{g})$} & \multirow{2}{*}{$\mathrm{pH}$} & \multirow{2}{*}{ Ref. } \\
\hline & & $\mathrm{As}(\mathrm{V})$ & As(III) & & \\
\hline Iron-impregnated chitosan granular & 10 & 22.5 & 16.1 & 7.0 & {$[22]$} \\
\hline $\mathrm{TiO}_{2}$-impregnated chitosan bead & 10 & $2.05^{\mathrm{a}}$ & $2.10^{\mathrm{b}}$ & $9.2^{\mathrm{a}}, 7.7^{\mathrm{b}}$ & {$[16]$} \\
\hline Iron oxide coated sponge & 5 & 4.5 & 3.85 & $6.5-7.3$ & {$[23,24]$} \\
\hline MICB & 50 & 35.7 & 35.3 & 6.8 & [19] \\
\hline MCNP & 50 & 65.5 & 60.2 & 6.8 & Our work \\
\hline
\end{tabular}

The labels "a" and "b" only denote the corresponding relationship. $C_{\text {initial }}$ is the initial concentration of arsenic $(\mathrm{mg} / \mathrm{L}) ; q_{e, \max }$ represents the maximum adsorption capacity of arsenic $(\mathrm{mg} / \mathrm{g})$.

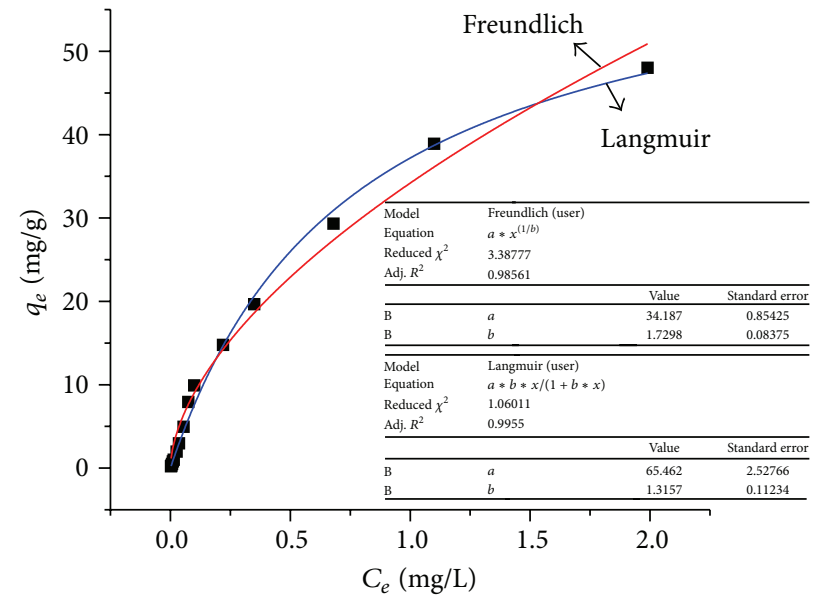

(a)

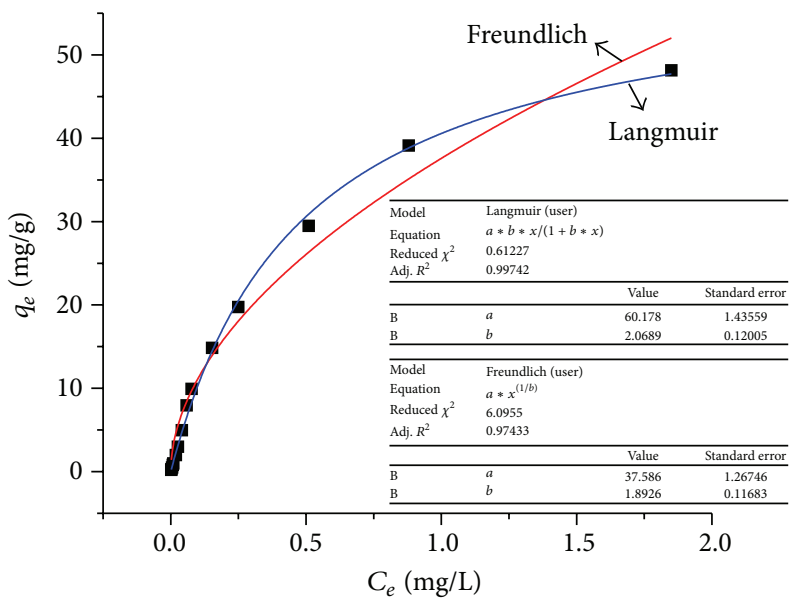

(b)

Figure 3: Adsorption isotherms of (a) As(V) and (b) As(III) by the MCNP with adsorbent dose of $1 \mathrm{~g} / \mathrm{L}$ at $\mathrm{pH} 6.8 \pm 0.2$ and room temperature. Blue solid lines represent the Langmuir model and red solid lines represent the Freundlich model.

the MCNP was $108.32 \mathrm{~m}^{2} / \mathrm{g}$, higher than other adsorbents; the second is the fact that the quantity of amino groups may be another influencing factor for the adsorption capacity due to the removal mechanism of chitosan. It is well known that the removal mechanism of chitosan for the arsenic mainly lies in the electrostatic attraction between the positive surface charges of the protonated chitosan amine functions and the negative charges of the arsenate ions $[19,25]$. The total amount of amino groups on MCNP was determined at about $1.93 \mathrm{mmol} / \mathrm{g}$ using the nitrogen-carbon ratio (N/C ratio) of 0.252 . Since the amine groups were involved in the hydrogen bonding of the chitosan and have been considered as the main group to remove the heavy metals, the maximum possible adsorption capacity of MCNP may attain about $144.75 \mathrm{mg} / \mathrm{g}$ (multiplication of atomic weight of As and the quantity of amino group).

These results demonstrated that the MCNP was effective for both $\mathrm{As}(\mathrm{V})$ and $\mathrm{As}(\mathrm{III})$ removal. In particular, it showed good adsorption performance for As(III), as most adsorbents reported previously were effective for $\mathrm{As}(\mathrm{V})$ adsorption, but not for the case of As(III) due to its uncharged form at most $\mathrm{pHs}[15,26]$. This is the advantage of the adsorbent since As(III) was more toxic and more difficult to remove from water than $\mathrm{As}(\mathrm{V})$, for the MCNP showed better conditions for the removal of As (just as relatively shorter immigration distance and abundance of accessible adsorption sites), which weaken the influence of arsenic charge to some extent. The detailed reasons need further investigation.

3.2. Regeneration of MCNP. Sodium hydroxide solution was generally used to regenerate the chitosan and its derivations [19]. The regeneration conditions were optimized as $0.15 \mathrm{~mol} / \mathrm{L}$ sodium hydroxide solution and $30 \mathrm{~min}$ regeneration time. Figure 4 shows the adsorption efficiency of the regenerated $\mathrm{MCNP}$ for $\mathrm{As}(\mathrm{V})$ and $\mathrm{As}(\mathrm{III})$ with initial arsenic concentration of $1 \mathrm{mg} / \mathrm{L}$ and adsorbent dose of $1 \mathrm{~g} / \mathrm{L}$ at $\mathrm{pH}$ $6.8 \pm 0.2$ for 10 times.

In the recycle study, The MCNP maintained $98.1 \%$ for $\mathrm{As}(\mathrm{V})$ and $95.6 \%$ for As(III) after one adsorption-desorption cycle, respectively. And after 10 cycles of reuse, the regenerated MCNP still retained about $97.5 \%$ and $95.3 \%$ for $\mathrm{As}(\mathrm{V})$ and $\mathrm{As}(\mathrm{III})$, respectively, which indicated that the MCNP could be readily regenerated by the sodium hydroxide solution and seldom adsorption capacity decreases during the regeneration. Similar results were gained for the regeneration of magnetic ion exchange resins (MIEX) [27]. Comparing the characteristics of the MIEX and MCNP, we could see that a similar feature existed between them, that is to say, the nonpore structure, which could avoid the block of pore inside the adsorbents; therefore, the regeneration effects could keep 


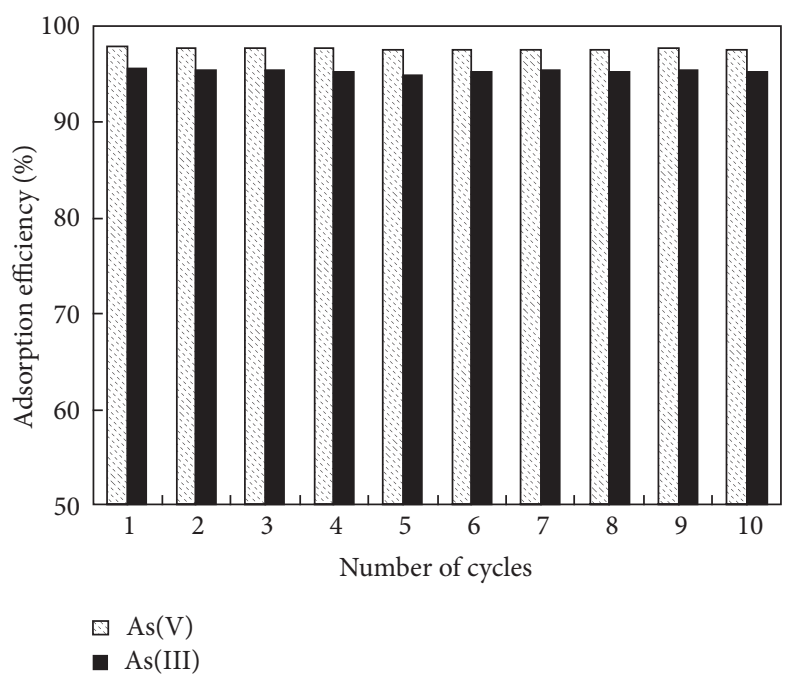

FIGURE 4: Adsorption efficiency of the regenerated MCNP for As(V) and As(III) with initial arsenic concentration of $1 \mathrm{mg} / \mathrm{L}$ and adsorbent dose of $1 \mathrm{~g} / \mathrm{L}$ at $\mathrm{pH} 6.8 \pm 0.2$ for 10 times.

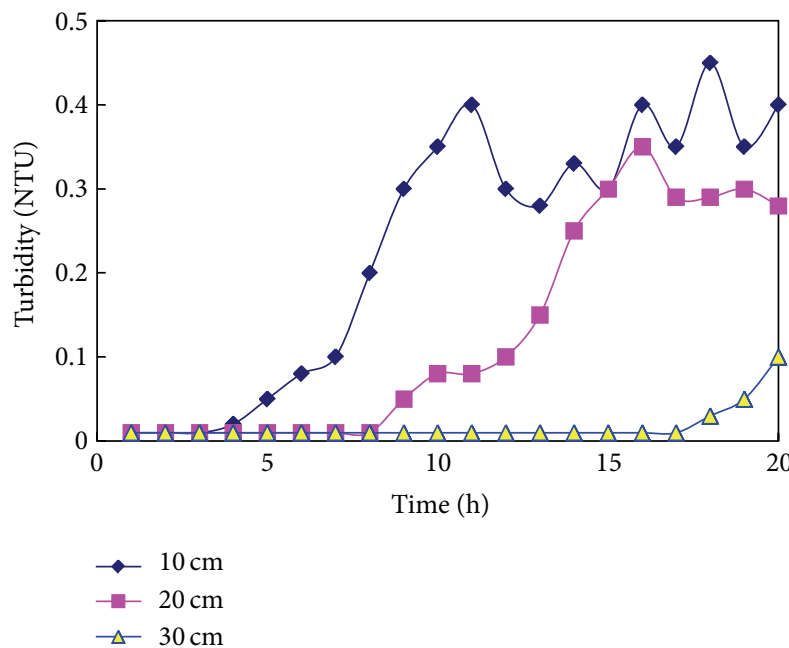

(a)

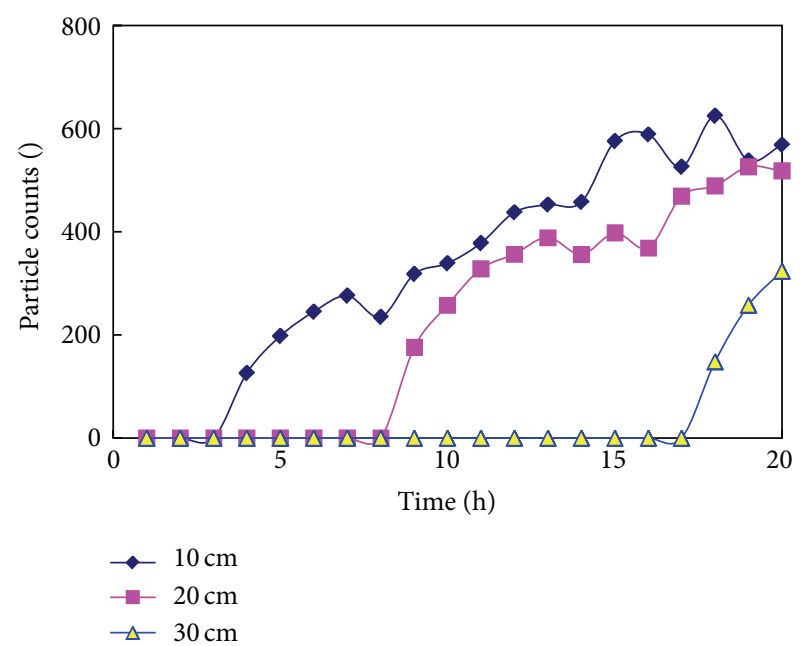

(b)

FIGURE 5: (a) Influence of iron powder depth on the turbidity of outlet. (b) Influence of iron powder depth on the total particle count of the outlet.

at a high degree. In all, MCNP showed better reusability for arsenic removal than former studies.

3.3. Separation of MCNP. Due to the typical characteristics of the particle, MCNP showed superior advantages to the other chitosan and derivations, including higher adsorption capacity and rate and better regeneration effect. However, one fatal demerit existing in the application of engineering was the difficult isolation with the product water. Due to smaller size and relatively low density, the MCNP could exist with water harmoniously, while the biological toxicity of nanoparticles had raised much concern [28, 29]. Although the external and induced magnetic field could strengthen the separation process and the nanoparticles could be nearly entirely separated from water at the magnetic field for its relatively higher saturation magnetization, it was limited to use in the continuous operation [30]. Therefore, new method to separate the MCNP effectively was needed. Filtration was one of effective ways to remove particles from water, so filter with specific diameter of iron powder may be one of better choices with the consideration of the particles' magnetism. However, seldom successful experience was found in the former studies, so the influences of diameter and depth of iron powder on the separation effects are discussed (Figures 5(a) and 5(b)).

The iron powder could intercept the particle of MCNP effectively and the effect was proportional to the depth of filter. Due to relatively higher saturation magnetization, the MCNP could adsorb onto the surface of iron powder immediately and accumulate together as the powder was the center. The pore size became smaller as the aggregation gets bigger, and the velocity of water grew higher accordingly. 

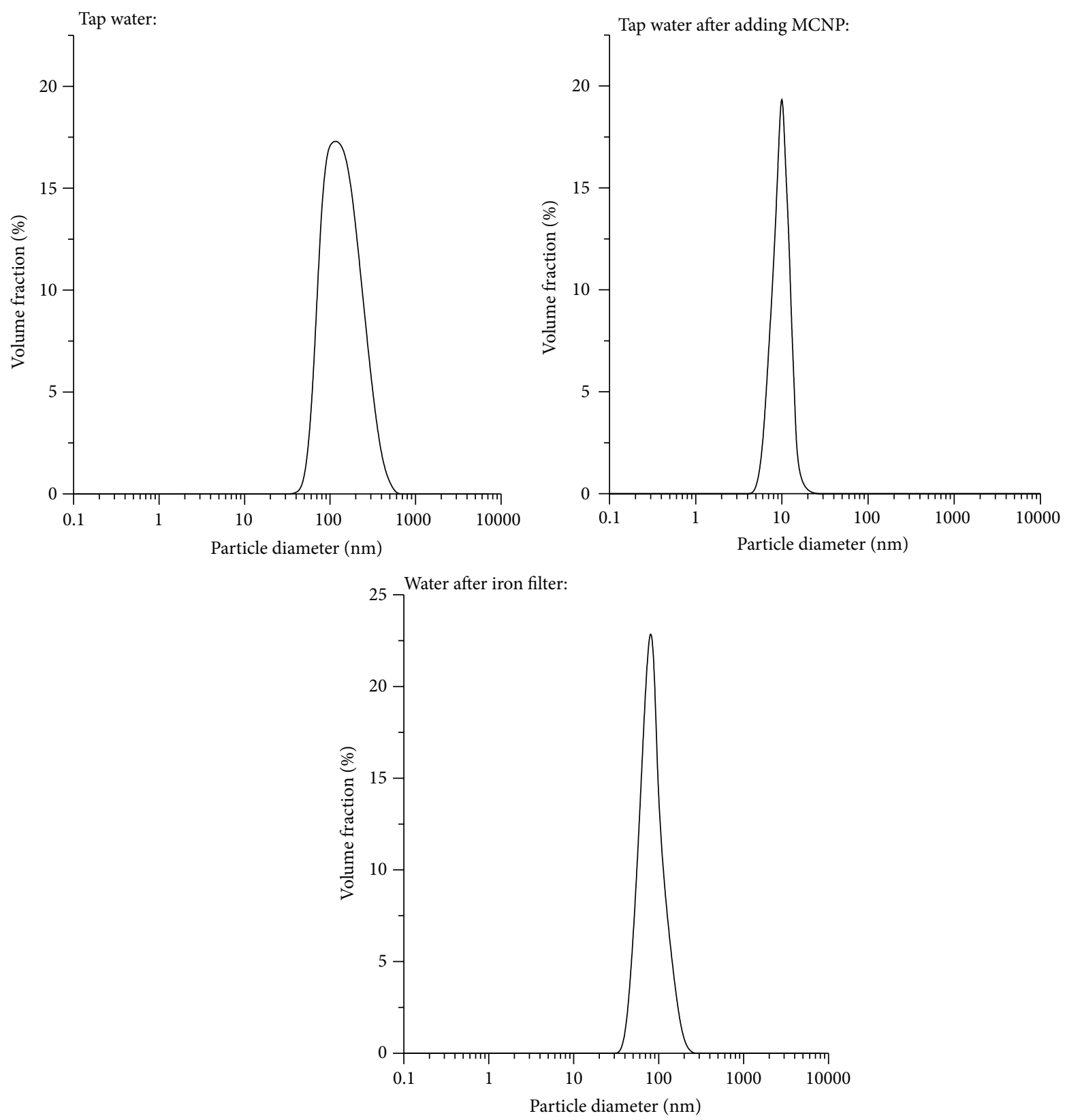

FIgURE 6: The size distribution of tap water, water adding MCNP, and water after iron filter.

When the velocity can overcome the attraction of the particles, some MCNP will come into the water and cause the higher turbidity. Figure 5(b) also testified the similar process. According to the demand of water treatment, $30 \mathrm{~cm}$ was the proper depth of the iron powder, for it needs not only to retain the particle effectively during the filtration but also to be stripped off entirely during the back-flush. Table 2 shows that the saturation magnetization of MCNP is $44.43 \mathrm{meu} / \mathrm{g}$, that is, weakly magnetic, which may cause poor separation through the way of iron powder. However, the separation effect was excellent even with a relatively short depth of iron powder filter. The reason may lie in that the particles of MCNP have evident tendency to aggregation due to their nanosize and most of the particles could be excluded by the iron powder filter with a depth of more than $30 \mathrm{~cm}$.

Figure 6 shows the particle size distribution of tap water and outflow of the iron filter. As the size distribution of pure water cannot be determined by the Zetasizer Nano ZS90 instrument, the tap water was used to investigate the removal effect of iron filter for the MCNP.

As seen from Figure 6, the size of particle in tap water was mainly focused in about $100 \mathrm{~nm}$ and converted to about $10 \mathrm{~nm}$ after addition of MCNP, which indicated that the size of MCNP was mainly focused on diameter of $10 \mathrm{~nm}$ and dominates in the all particles. However, the particles size distribution before and after the ion filter adding MCNP was 


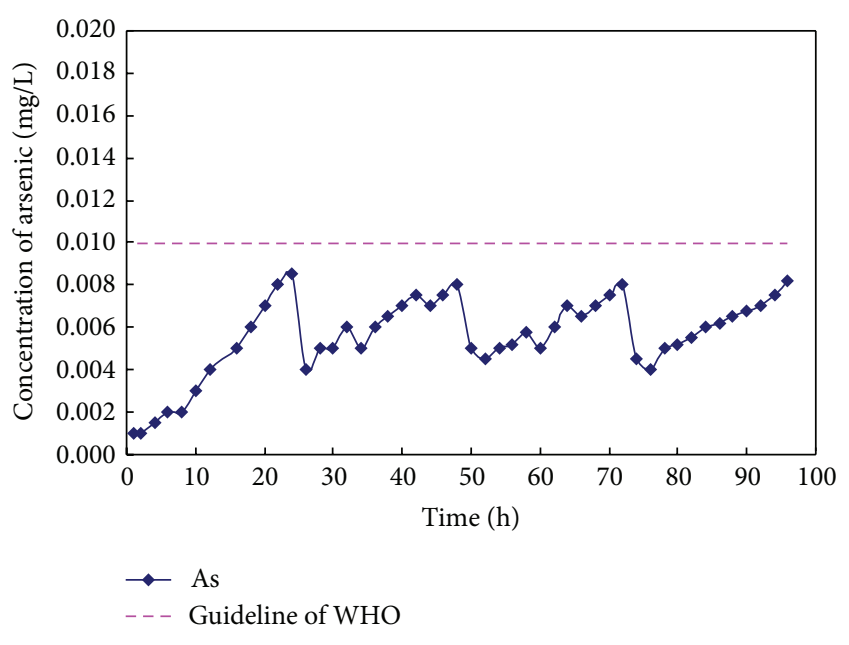

Figure 7: Removal efficiency of the new continuous-operation instrument to treat the underground water sample from Inner Mongolia.

similar, that is to say the MCNP were separated entirely. It is regretful that the ZS90 instrument could not determine the nanoparticles counts directly, but the determination results also verified the perfect separation performance for the MCNP.

3.4. Continuous Operation to Remove Arsenic from Raw Water. To verify the removal effects of MCNP for the arsenic in the raw water and the separation effect of MCNP, continuous dynamic adsorption experiment is used to treat the raw water taken from the water plant in Bayannur city. The concentration of arsenic in the outlet water was shown in Figure 7. As shown in Figure 7, the concentration of arsenic in the outlet water was about $5-8 \mu \mathrm{g} / \mathrm{L}$ at $800 \mathrm{BV}$, which met the guideline limit of arsenic in drinking water regulated by the WHO $(10 \mu \mathrm{g} / \mathrm{L})$. Some other advantages were found in the operation of instrument. Firstly, the hydraulic retention time (HRT) was relatively short and could decrease the volume of the reactor; second, the regeneration method was simple so as to guarantee the continuous operation of the instrument; third, the MCNP can be separated effectively by the filter with iron powder and can be recycled through the way of backwashing. In addition, one particular phenomenon was found in the continuous operation. Although the pore size of sand core filter (G2) was about $10-15 \mu \mathrm{m}$, it can intercept most of the nanometer MCNP, which may be caused by the aggregation of magnetic particles and pulse aeration to put the aggregator back to the main solution. The backwash period of the iron powder filter was extended to about $25 \mathrm{~h}$ due to the primary exclusion of sand core filter. The wavy removal curve was mainly caused by the regeneration of the MCNP intercepted in the filter after one backwash period.

In all, although the diameter of MCNP was about $10 \mathrm{~nm}$, it can be easily isolated from water due to its higher saturation magnetization and can be used to remove arsenic effectively in the real operation.

\section{Conclusion}

This study demonstrated that MCNP could be used as an effective adsorbent for arsenic removal. MCNP presented better arsenic adsorption performance within relatively short time than other adsorbents and the adsorption kinetics followed pseudo-second-order kinetic model. The adsorption isotherm could be described well by the Langmuir model, and the maximum capacity was calculated to be $65.5 \mathrm{mg} / \mathrm{g}$ for $\mathrm{As}(\mathrm{V})$ and $60.2 \mathrm{mg} / \mathrm{g}$ for $\mathrm{As}(\mathrm{III})$ at $\mathrm{pH} 6.8$, respectively, which was reasonably good compared with that of other granular adsorbents reported previously. And the MCNP could retain more than $95 \%$ of the original adsorption capacity for both $\mathrm{As}(\mathrm{V})$ and $\mathrm{As}(\mathrm{III})$ after 10 cycles of reuse. A new style iron powder filter was established to effectively separate MCNP from water. A field application of the adsorbent for removal of arsenic in groundwater demonstrated that it could be promising for practical drinking water treatment.

\section{Highlights}

(i) Magnetic chitosan nanoparticle showed better removal performance for the arsenic.

(ii) A new separation method for magnetic nanoparticles was first established.

(iii) A new continuous-operation instrument was used to remove arsenic from raw water.

\section{Conflict of Interests}

The authors declare that there is no conflict of interests regarding the publication of this paper.

\section{Acknowledgments}

This work was supported by the National Major Project of Science \& Technology Ministry of China (Grant no. 2012ZX07403-001), National Nature Science Foundation of China (no. 51378174), and Project Funded by the Priority Academic Program Development of Jiangsu Higher Education Institutions.

\section{References}

[1] H. M. Anawar, J. Akai, K. M. G. Mostofa, S. Safiullah, and S. M. Tareq, "Arsenic poisoning in groundwater: health risk and geochemical sources in Bangladesh," Environment International, vol. 27, no. 7, pp. 597-604, 2001.

[2] U. K. Chowdhury, B. K. Biswas, T. R. Chowdhury et al., "Groundwater arsenic contamination in Bangladesh and West Bengal, India," Environmental Health Perspectives, vol. 108, no. 5, pp. 393-407, 2000.

[3] A. H. Smith, E. O. Lingas, and M. Rahman, "Contamination of drinking-water by arsenic in Bangladesh: a public health emergency," Bulletin of the World Health Organization, vol. 78, no. 9, pp. 1093-1103, 2000.

[4] L. Rodríguez-Lado, G. Sun, M. Berg et al., "Groundwater arsenic contamination throughout China," Science, vol. 341, no. 6148, pp. 866-868, 2013. 
[5] Y. Xia and J. Liu, "An overview on chronic arsenism via drinking water in PR China," Toxicology, vol. 198, no. 1-3, pp. 25-29, 2004.

[6] H. A. Michael, "An arsenic forecast for China," Science, vol. 341, no. 6148, pp. 852-853, 2013.

[7] A. Davis, M. V. Ruby, M. Bloom, R. Schoof, G. Freeman, and P. D. Bergstrom, "Mineralogic constraints on the bioavailability of arsenic in smelter-impacted soils," Environmental Science and Technology, vol. 30, no. 2, pp. 392-399, 1996.

[8] Y. Masue, R. H. Loeppert, and T. A. Kramer, "Arsenate and arsenite adsorption and desorption behavior on coprecipitated aluminum: iron hydroxides," Environmental Science and Technology, vol. 41, no. 3, pp. 837-842, 2007.

[9] M. B. Baskan and A. Pala, "Determination of arsenic removal efficiency by ferric ions using response surface methodology," Journal of Hazardous Materials, vol. 166, no. 2-3, pp. 796-801, 2009.

[10] A. H. Malik, Z. M. Khan, Q. Mahmood, S. Nasreen, and Z. A. Bhatti, "Perspectives of low cost arsenic remediation of drinking water in Pakistan and other countries," Journal of Hazardous Materials, vol. 168, no. 1, pp. 1-12, 2009.

[11] V. Fierro, G. Muñiz, G. Gonzalez-Sánchez, M. L. Ballinas, and A. Celzard, "Arsenic removal by iron-doped activated carbons prepared by ferric chloride forced hydrolysis," Journal of Hazardous Materials, vol. 168, no. 1, pp. 430-437, 2009.

[12] R. P. Liu, W. X. Gong, H. C. Lan, T. M. Yang, H. J. Liu, and J. H. Qu, "Simultaneous removal of arsenate and fluoride by iron and aluminum binary oxide: competitive adsorption effects," Separation and Purification Technology, vol. 92, pp. 100-105, 2012.

[13] K. C. M. Kwok, L. F. Koong, G. Chen, and G. McKay, "Mechanism of arsenic removal using chitosan and nanochitosan," Journal of Colloid and Interface Science, vol. 416, pp. 1-10, 2014.

[14] A. Gupta, M. Yunus, and N. Sankararamakrishnan, "Zerovalent iron encapsulated chitosan nanospheres-a novel adsorbent for the removal of total inorganic Arsenic from aqueous systems," Chemosphere, vol. 86, no. 2, pp. 150-155, 2012.

[15] J. S. Yamani, S. M. Miller, M. L. Spaulding, and J. B. Zimmerman, "Enhanced arsenic removal using mixed metal oxide impregnated chitosan beads," Water Research, vol. 46, no. 14, pp. 4427-4434, 2012.

[16] S. M. Miller and J. B. Zimmerman, "Novel, bio-based, photoactive arsenic sorbent: $\mathrm{TiO}_{2}$-impregnated chitosan bead," Water Research, vol. 44, no. 19, pp. 5722-5729, 2010.

[17] J. Q. Ma, Y. Shen, C. S. Shen, Y. Z. Wen, and W. P. Liu, "Aldoping chitosan-Fe(III) hydrogel for the removal of fluoride from aqueous solutions," Chemical Engineering Journal, vol. 248, pp. 98-106, 2014.

[18] R. N. Shinde, A. K. Pandey, R. Acharya et al., "Chitosantransition metal ions complexes for selective arsenic $(\mathrm{V})$ preconcentration," Water Research, vol. 47, no. 10, pp. 3497-3506, 2013.

[19] J. Wang, W. Xu, L. Chen, X. Huang, and J. Liu, "Preparation and evaluation of magnetic nanoparticles impregnated chitosan beads for arsenic removal from water," Chemical Engineering Journal, vol. 251, pp. 25-34, 2014.

[20] C. L. Dong, W. Chen, and C. Liu, "Preparation of novel magnetic chitosan nanoparticle and its application for removal of humic acid from aqueous solution," Applied Surface Science, vol. 292, pp. 1067-1076, 2014.

[21] C. L. Dong, W. Chen, C. Liu, Y. Liu, and H. C. Liu, "Synthesis of magnetic chitosan nanoparticle and its adsorption property for humic acid from aqueous solution," Colloids and Surfaces A:
Physicochemical and Engineering Aspects, vol. 446, pp. 179-189, 2014.

[22] A. Gupta, V. S. Chauhan, and N. Sankararamakrishnan, "Preparation and evaluation of iron-chitosan composites for removal of $\mathrm{As}(\mathrm{III})$ and $\mathrm{As}(\mathrm{V})$ from arsenic contaminated real life groundwater," Water Research, vol. 43, no. 15, pp. 3862-3870, 2009.

[23] T. V. Nguyen, S. Vigneswaran, H. H. Ngo, and J. Kandasamy, "Arsenic removal by iron oxide coated sponge: experimental performance and mathematical models," Journal of Hazardous Materials, vol. 182, no. 1-3, pp. 723-729, 2010.

[24] W. S. Wan-Ngah, M. A. K. M. Hanafiah, and S. S. Yong, "Adsorption of humic acid from aqueous solutions on crosslinked chitosan-epichlorohydrin beads: kinetics and isotherm studies," Colloids and Surfaces B: Biointerfaces, vol. 65, no. 1, pp. 18-24, 2008.

[25] E. Guibal, "Interactions of metal ions with chitosan-based sorbents: a review," Separation and Purification Technology, vol. 38, no. 1, pp. 43-74, 2004.

[26] G. S. Zhang, H. J. Liu, R. P. Liu, and J. H. Qu, "Adsorption behavior and mechanism of arsenate at Fe-Mn binary oxide/water interface," Journal of Hazardous Materials, vol. 168, no. 2-3, pp. 820-825, 2009.

[27] V. Fierro, G. Muniz, M. Drikas, M. Dixon, and J. Morran, "Long term case study of MIEX pre-treatment in drinking water; understanding NOM removal," Water Research, vol. 45, no. 4, pp. 1539-1548, 2011.

[28] T. Phenrat, T. C. Long, G. V. Lowry, and B. Veronesi, "Partial oxidation ("Aging") and surface modification decrease the toxicity of nanosized zerovalent Iron," Environmental Science and Technology, vol. 43, no. 1, pp. 195-200, 2009.

[29] J. W. Chen, Z. M. Xiu, G. V. Lowry, and P. J. J. Alvarez, "Effect of natural organic matter on toxicity and reactivity of nano-scale zero-valent iron," Water Research, vol. 45, no. 5, pp. 1995-2001, 2011.

[30] C. T. Yavuz, J. T. Mayo, W. W. Yu et al., "Low-field magnetic separation of monodisperse $\mathrm{Fe}_{3} \mathrm{O}_{4}$ nanocrystals," Science, vol. 314, no. 5801, pp. 964-967, 2006. 

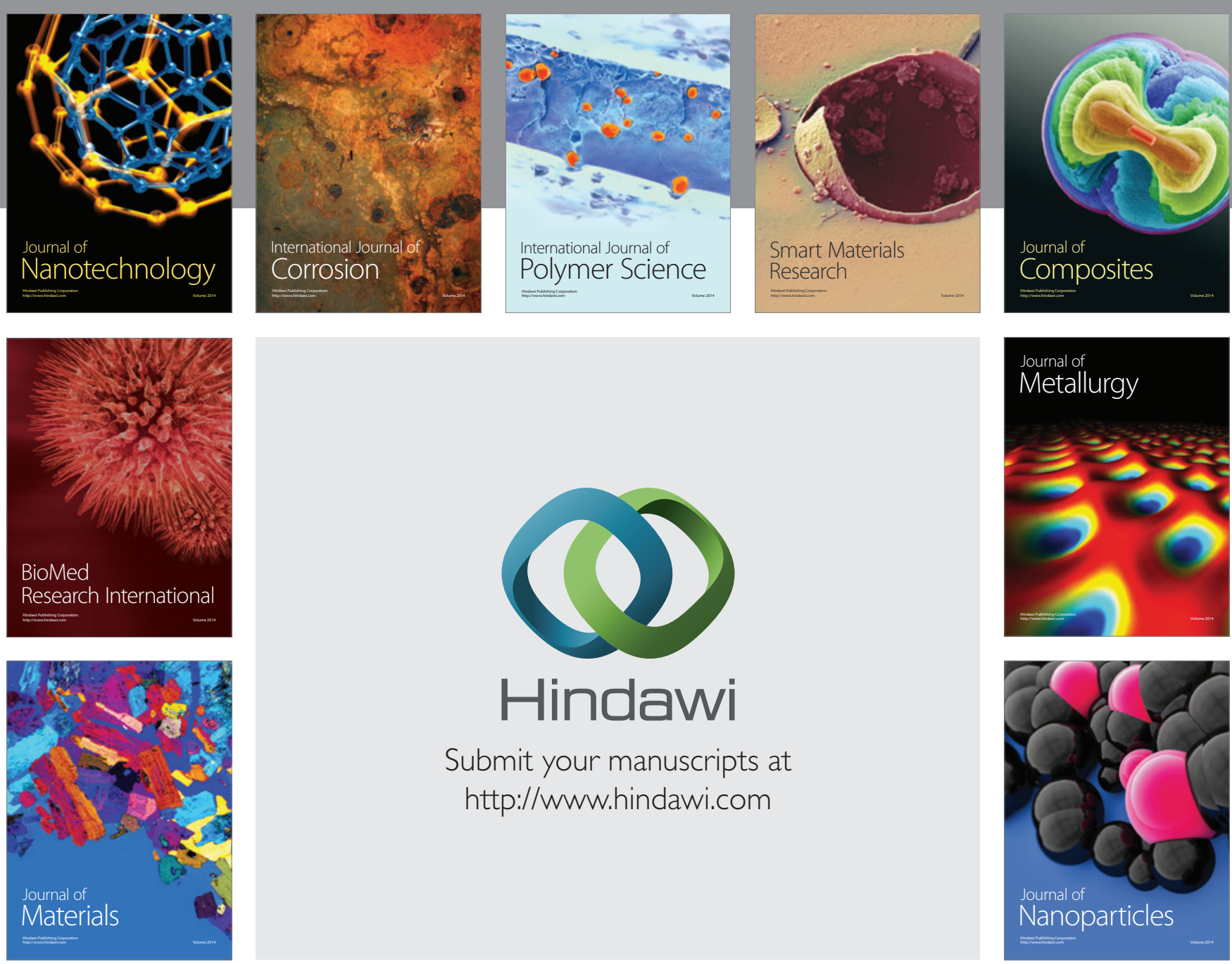

Submit your manuscripts at http://www.hindawi.com
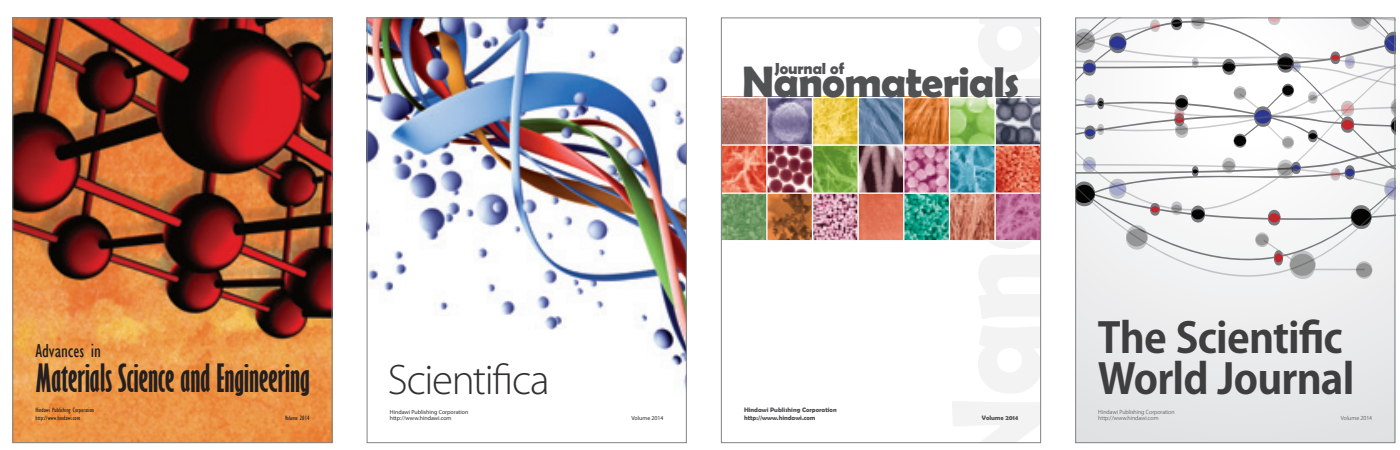

\section{The Scientific World Journal}
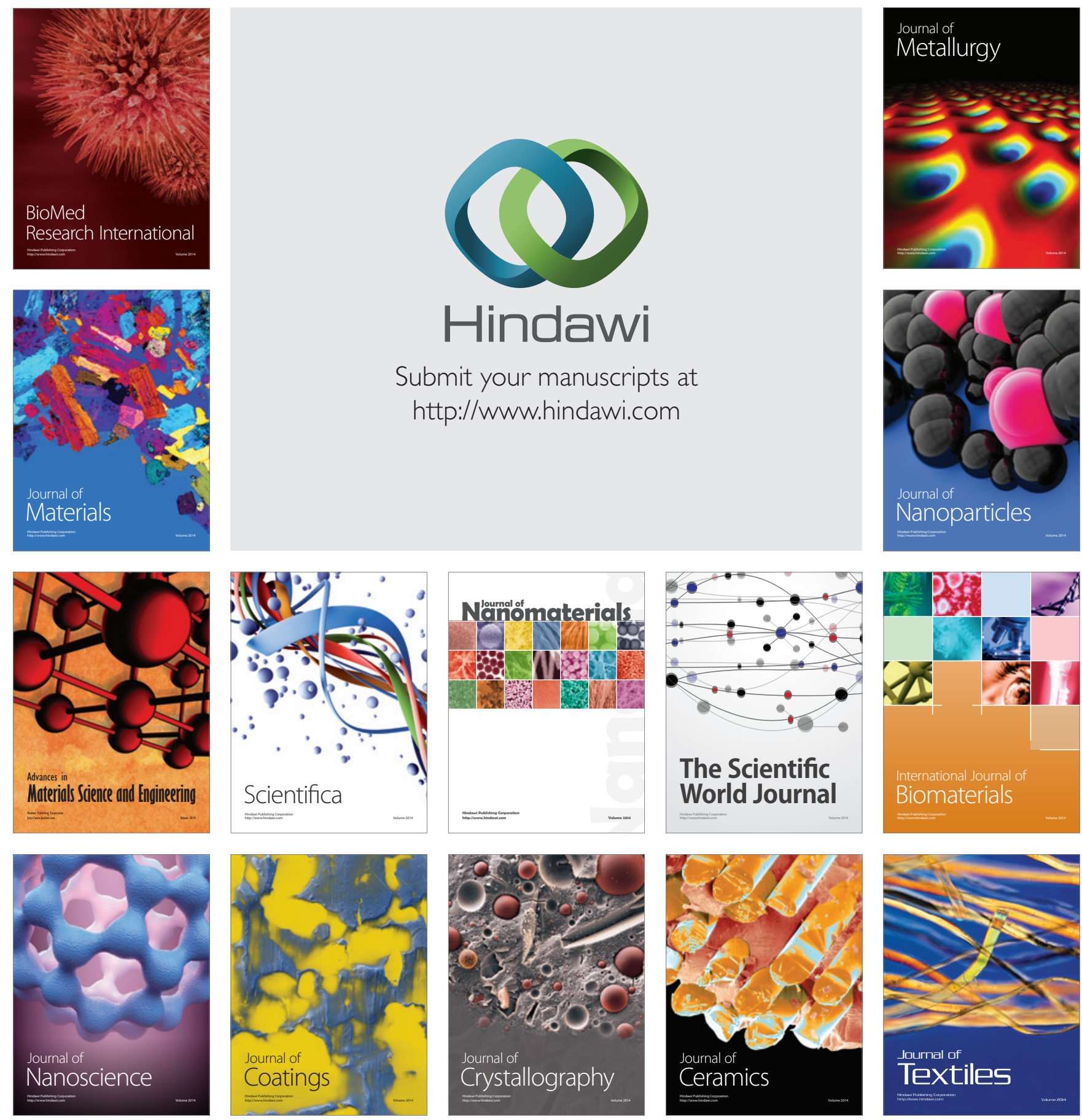